\title{
Glass-Blown Pyrex Resonator with Compensating Ti Coating for Reduction of TCF
}

\author{
Joan Giner ${ }^{1,2}$, Lorenzo Valdevit ${ }^{1}$, Andrei. M. Shkel ${ }^{1,2}$ \\ ${ }^{1}$ Mechanical and Aerospace Engineering Department, University of California, Irvine, CA, USA \\ ${ }^{2}$ Microsystems Laboratory, University of California, Irvine, CA, USA \\ jginerde@uci.edu, valdevit@uci.edu, andrei.shkel@uci.edu
}

\begin{abstract}
This paper demonstrates that the Thermal Coefficient of resonant Frequency (TCF) of a micro glass-blown Pyrex spherical resonator can be substantially reduced by the application of a titanium (Ti) coating. Finite Elements Analysis (FEA) is used to demonstrate that the temperature dependence of the Young's modulus of the shell material is the dominant parameter affecting the TCF of the resonator, clearly suggesting the use of a metallic compensating layer. Experimental characterization demonstrates that the TCF of a Pyrex glassblown resonator is reduced by $70 \%$ (from $73 \mathrm{ppm} /{ }^{\circ} \mathrm{C}$ to $24 \mathrm{ppm} /{ }^{\circ} \mathrm{C}$ ) by the application of a 1.33 um thick layer of $\mathrm{Ti}$. It is predicted by FEM that for a Ti layer thickness on the order of $2.5 \mu \mathrm{m}$, the TCF will fall below $10 \mathrm{ppm}$, an acceptable value for high performance resonators. This investigation is a step forward in the quest to employ the desirable properties of micro-blown resonators, such as high symmetry, manufacturing tolerances and environmental robustness.
\end{abstract}

Keywords-glassblowing, resonators, TCF compensation, dynamic MEMS.

\section{INTRODUCTION}

Micro-Electro-Mechanical Systems (MEMS) resonators are desirable for a wide variety of applications, including signal processing, timing, frequency control, and inertial sensing [1]. Several silicon MEMS resonators are currently on the market [2-3]. The vast majority of MEMS resonators are fabricated utilizing silicon as a structural material and using photolithography and DRIE techniques for defining the features. The dimensional resolution of these techniques is limited by fabrication imperfections introduced by etching, such as DRIE-induced scalloping, surface roughness, and the intrinsic limits of the aspect ratio of features. As a result, the fabrication of highly symmetric, frequency-matched devices with exceptionally high quality factor becomes extremely challenging. These factors motivate the investigation of alternative fabrication approaches that allow the development of non-planar MEMS resonator architectures with increased symmetry, reduced roughness of structures, and increased aspect ratios - all accomplished simultaneously.

Recently, there has been significant interest in the development of 3-D MEMS spherical and hemispherical resonators for use in timing and inertial sensing applications. Photolithography and DRIE based approaches have been used to fabricate silicon oxide hemispherical resonators using silicon molds, resulting in quality factors (Q) as high as 20,000 at a resonant frequency of $22 \mathrm{kHz}$ [4]. The same fabrication approach has been demonstrated to build polysilicon resonators for inertial application, with Q's around 8000 at a resonant frequency of $416 \mathrm{kHz}$ [5]. Plastic deformation of metallic glasses to achieve spherical structures has been explored by using a blow-molding technique [6]. The use of low ThermoElastic Damping (TED) materials, such as Fused Silica (FS), as structural material has also being explored; Q factors above 100,000 at frequencies around $10 \mathrm{kHz}$ have been demonstrated [7]; processing of these materials requires temperatures in excess of $1,600^{\circ} \mathrm{C}$.

A highly parallel glass-blowing process developed in the UC Irvine Microsystems Laboratory allows shaping of fused silica glass to create highly symmetric structures with resonant frequencies in the range from $1 \mathrm{kHz}$ to $1 \mathrm{MHz}$ [8]. Although high Q factor (several thousands) and excellent symmetry was demonstrated (resulting in frequency splits as low as $0.15 \mathrm{~Hz}$ ), dimensional constraints of the hemispherical shapes may not lead to the highest fxQ product and environmental robustness. By fabrication of quasi-spherical structures using micro glassblowing techniques [9], we are able to build spherical resonators with integrated electrodes and with low order resonant frequencies about $1 \mathrm{MHz}$ for resonators [10] and inertial sensors [11].

The high temperature dependence of the resonant frequency (TCF) in low TED glass resonators (fused quartz or borosilicate glass) is a major performance-limiting factor, making it impossible to achieve acceptable frequency stability [12], as practical frequency stability $<100 \mathrm{ppm}$ over the range of operating conditions is required by most practical applications [13]. Several approaches exist to compensate for the frequency drift. They can be divided in two categories: (i) resonator-level solutions (engineering of Young's modulus [14], doping [15], compensation utilizing electrostatic spring softening [16], and temperature stabilization by ovenization [17]), and (ii) oscillator concepts based on frequency synthesis [18] and impedance loading [19]. Most often, several approaches are combined together to maximize temperature stability.

In this paper, we investigate the application of titanium coating on spherical glass-blown resonators for temperature compensation. Figure 1 shows a spherical resonator surrounded by a toroidal electrode structure. In the proposed design, the 3D electrodes are used to exert the electrostatic force to drive the mechanical resonance of the central sphere and to read-out its velocity. The application of the Ti layer is anticipated to 


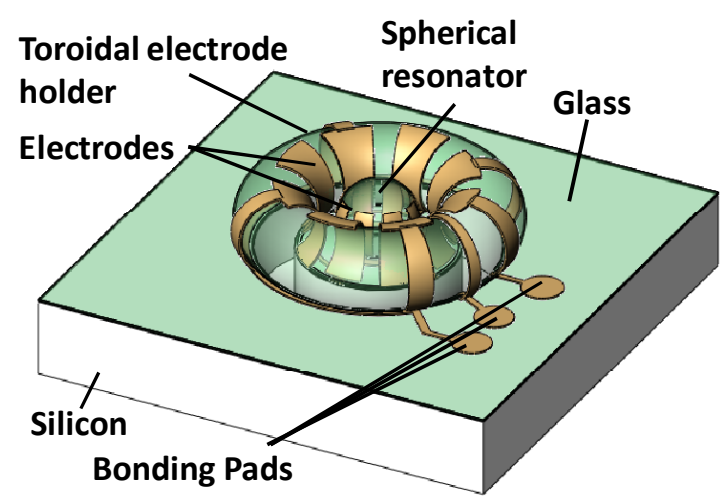

Figure 1. Concept of a spherical resonator with integrated 3D electrodes

simultaneously control the TCF of the glass and provide the electrical conductive layer required to electrically bias the central spherical resonator

\section{TCF MODELING}

The Temperature Coefficient of resonant Frequency (TCF) determines the change of the resonant frequency of MEMS devices due to environmental variations in temperature. Three factors contribute to the frequency change of a glass-blown resonator: (i) dimensional changes in the resonator due to thermal expansion; (ii) thermal stresses resulting from Thermal Expansion Coefficient (CTE) mismatch between the glass and the silicon substrate, and (iii) intrinsic variations in Young's modulus of the glass with temperature (Temperature Coefficient of Young's Modulus, or TCE).

The thermo-mechanical behavior of the spherical resonator has been modeled with Finite Elements Analysis (FEA) using a commercial package COMSOL Multiphysics. The resonator is modeled as a $480 \mu \mathrm{m}$ radius sphere with $92 \%$ sphericity and non-uniform shell thickness (15um at the top, tapering to 40 $\mu \mathrm{m}$ near the anchor point). The silicon substrate is not included in the modeling. The thermo-mechanical properties of the materials used in modeling have been extracted from the COMSOL library and are reported in Table I. To investigate the dependence of both the TCE and CTE parameters on the TCF, the $n=2$ mode of a Fused Silica and Pyrex spherical resonator has been modeled and simulated.

Figure 2 shows the resonant frequency change of the $n=2$ mode of a spherical resonator due to the variation in temperature. For Pyrex and Fused Silica, two modeling experiments have been performed. In the first experiment we

TABLE I. THERMAL POPERTIES OF MATERIAL (OBTAINED FROM [20] AND THE MATERIAL LIBRARY BUILT IN COMSOL MULTIPHYSICS)

\begin{tabular}{|l|c|c|c|}
\hline \multicolumn{1}{|c|}{ Material } & $\begin{array}{c}\text { Young's } \\
\text { Modulus }\left(\mathbf{2} \mathbf{2 4}^{\circ} \mathbf{C}\right)\end{array}$ & $\mathbf{C T E , \boldsymbol { \alpha }}$ & TCE $(\mathbf{p p m} / \mathbf{C})$ \\
\hline Fused Silica & $73 \mathrm{GPa}$ & $0.25 \mathrm{ppm} / \mathrm{C}$ & +175 \\
\hline Borosilicate & $60 \mathrm{GPa}$ & $3.05 \mathrm{ppm} / \mathrm{C}$ & +105 \\
\hline Silicon & $170 \mathrm{GPa}$ & $2.6 \mathrm{ppm} / \mathrm{C}$ & -63 \\
\hline Pyrex 7740 & $63 \mathrm{GPa}$ & $3.05 \mathrm{ppm} / \mathrm{C}$ & +105 \\
\hline Titatium & $128 \mathrm{GPa}$ & $8.6 \mathrm{ppm} / \mathrm{C}$ & -328 \\
\hline
\end{tabular}

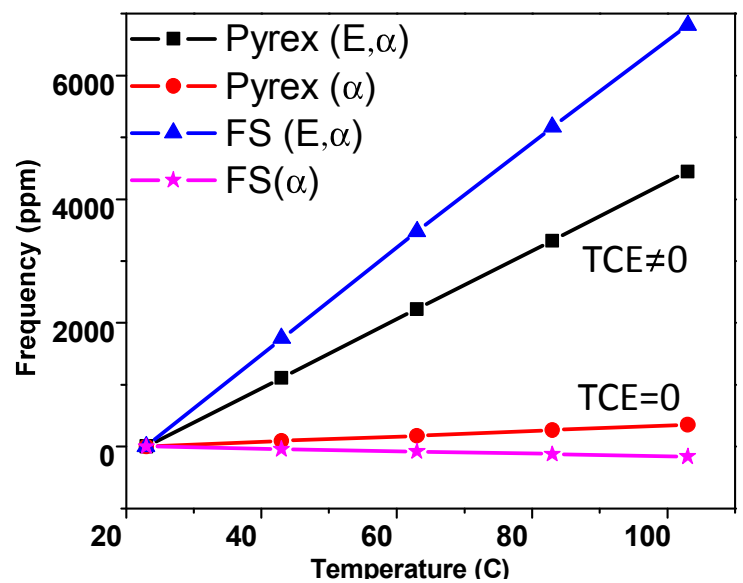

Figure 2. Modeled TCF for Pyrex and fused silica. Results shows the effect of the temeperature coefficient of Young's modulus

ignored the temperature dependence of the Young's modulus (TCE $=0$ in Figure 2), highlighting the TCF contribution from CTE dimensional changes. In the second modeling experiment we included the effect of both the TCE and the CTE. Two key results emerged: (a) the contribution of the temperature coefficient of the Young's modulus is the dominant effect, resulting in a large positive TCF for both materials; (b) when all factors are included, the TCF of fused silica $\left(85.1 \mathrm{ppm} /{ }^{\circ} \mathrm{C}\right)$ is substantially larger than that of Pyrex $\left(55.5 \mathrm{ppm} /{ }^{\circ} \mathrm{C}\right)$.

\section{ENGINEERED TCF}

We explored the composite Young's modulus to compensate the TCF. This technique is based on the fabrication of composite structural hybrid structures, encompassing at least two layers of different materials with opposite TCE. Metals are perfect candidates for compensating layers, as in addition to their negative TCE, metals have large electrical conductivity and hence can be used as electrode structures. Among all metals, titanium presents one of the highest negative TCE

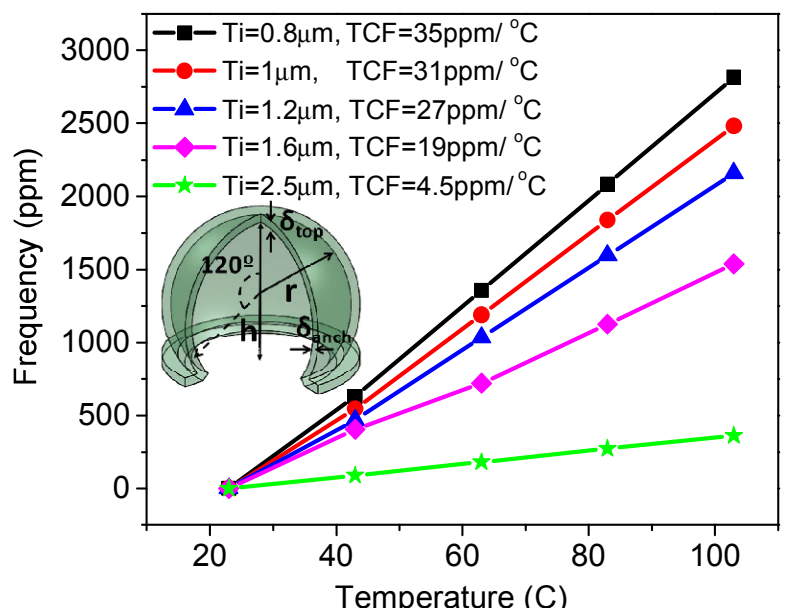

Figure 3. Modeling results of the effect of the titanium compensation layer on $\mathrm{r}=480 \mu \mathrm{m}, \mathrm{h}=850 \mu \mathrm{m}, \delta_{\mathrm{top}}=15 \mu \mathrm{m}, \delta_{\text {anch }}=40 \mu \mathrm{m}$ Pyrex spherical shells, where $\mathrm{r}, \mathrm{h}, \delta_{\text {top }}$ and $\delta_{\text {anch }}$ are radius, height, thicknes of the top of the shell and thickness of the shell near to the anchor point, respectively. 


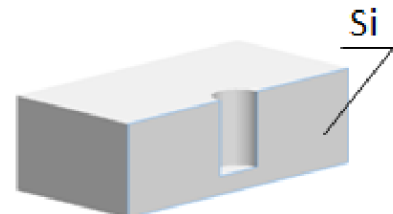

a)

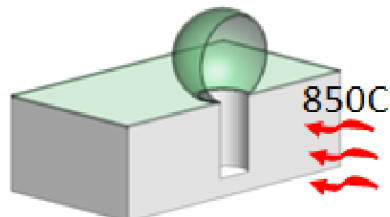

c)

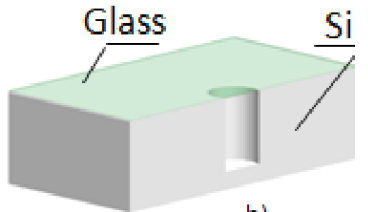

b)

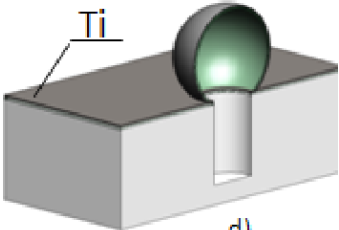

d)
Figure 4. Fabrication flow of the temperature compensated spherical resonator, excluding a step for electrodes patterning.

(Table I), allowing significant compensation with minimum thickness. Figure 3 shows the simulation results for titaniumcoated Pyrex resonators. All geometric parameters are the same for all modeling results. Notice that $0.8 \mathrm{um}$ of Ti reduces the TCF of the resonator from $55.5 \mathrm{ppm} /{ }^{\circ} \mathrm{C}$ to $35 \mathrm{ppm} /{ }^{\circ} \mathrm{C}$, and a TCF of less than $10 \mathrm{ppm} /{ }^{\circ} \mathrm{C}$ can be achieved by using $2.5 \mathrm{um}$ of Ti.

A detailed description of the fabrication process for microglass-blown resonators can be found in [10]. Figure 4 shows a simplified scheme of the fabrication process that includes the compensation metal layer deposition. A silicon wafer is DRIE etched, (a), and subsequently anodically bonded to a $200 \mathrm{um}$ -

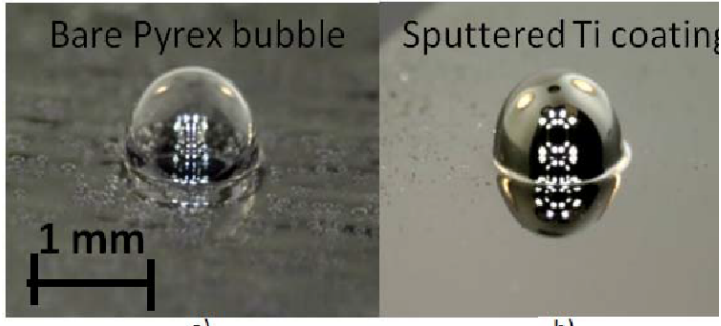

a)

b)

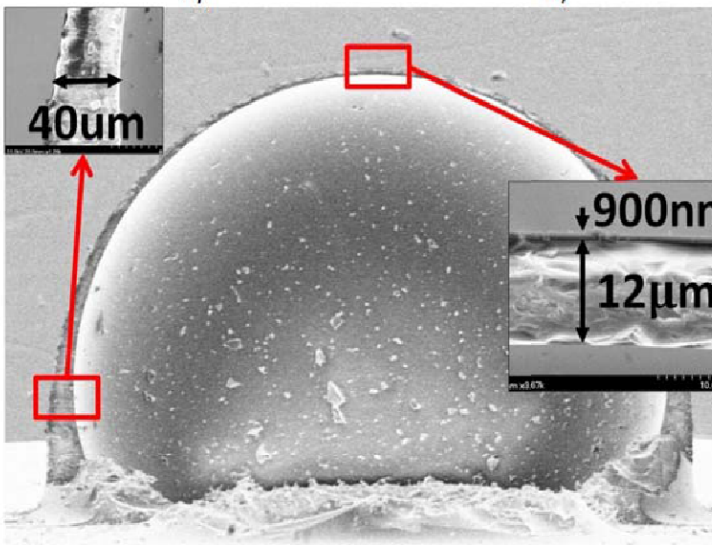

$11.0 \mathrm{kV} 12.0 \mathrm{~mm} \times 100$

500 um

Figure 5. Optical images of the spherical resoantor a) before and b) after the Ti coating deposition. c) shows a cross section SEM image of a coatied spherical resoantor.

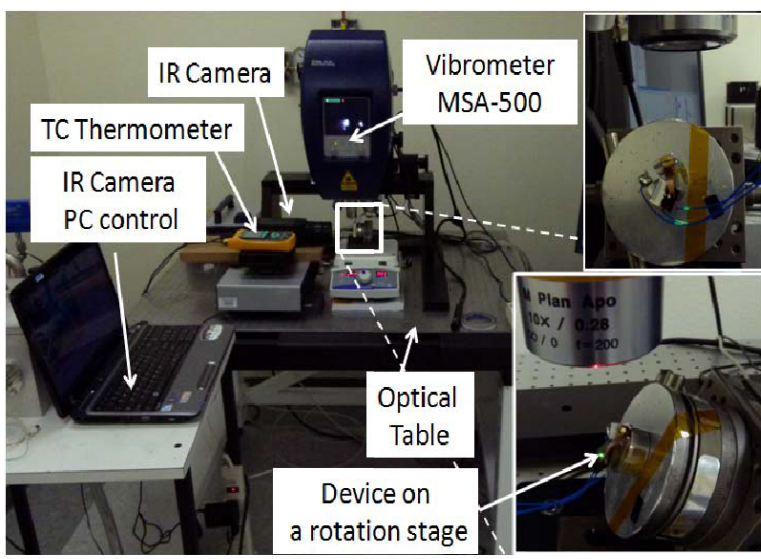

Figure 6. In air non-contact characterization set up.

thick Pyrex wafer, (b). Then, a glass-blowing step is performed, (c), and finally a $\mathrm{Ti}$ layer is sputtered (using a Denton Sputterer), (d). Figure 5 shows the resonator before and after the sputtering step, (a) and (b) respectively; and a SEM image of the cross-section after the sputtering step, (c).

\section{CHARACTERIZATION}

The characterization set-up is shown in Figure 6. The device is mounted on a rotary stage and placed on a hotplate. The vibration is induced using a piezo-disk. Temperature of the die is monitored using a contact thermocouple, while the temperature of the glass bubble is monitored by an infrared camera. A Polytec MSA-500 vibrometer was used to measure the velocity of vibration of the spherical resonator in response to piezoelectric excitation in a direction perpendicular to the substrate. Four different devices have been characterized, with different thicknesses of the titanium layer. Although all devices were otherwise nominally identical, small deviations in radius resulted in slight changes in their resonant frequencies (Table II).

Figure 7 shows the experimental results of the frequency drift for the $\mathrm{n}=2$ mode for 4 different spherical resonators. The

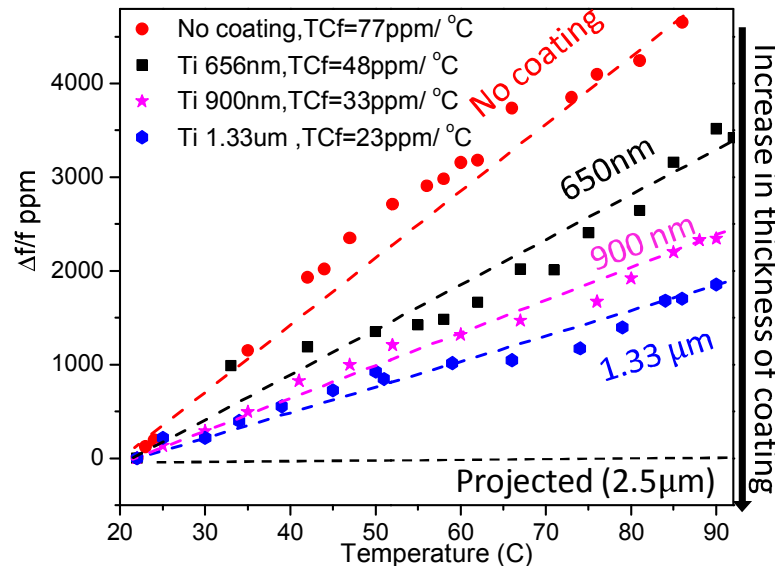

Figure 7. Experiemental results of frequency variation inspherical resonator with temeperature. The TCF values have been extracted form the measurements. 
TABLE II. FABRICATION FLOW OF THE TEMPERATURE COMPENSATED SPHERICAL RESONATOR, EXCLUDING A STEP FOR ELECTRODES PATTERNING

\begin{tabular}{|c|c|c|c|c|c|c|}
\hline \multirow{2}{*}{ Device } & \multirow{2}{*}{ Ti coating(um) } & \multicolumn{2}{|c|}{ Frequency $\mathbf{( H z )}(\mathbf{T}=\mathbf{2 3 C K})$} & \multirow{2}{*}{$\mathbf{T C f}(\boldsymbol{\alpha}, \mathbf{E})(\mathbf{p p m} / \mathbf{C})$} & $\mathbf{N}=\mathbf{2}$ & $\mathbf{N}$ \\
\hline 1 & 0 & $1.577700 \mathrm{E} 6$ & $1.785236 \mathrm{E} 6$ & $73 \pm 2.6$ & 270 & 285 \\
\hline 2 & 0.656 & $1.49 \mathrm{E} 6$ & $1.662774 \mathrm{E} 6$ & $48.5 \pm 1.6$ & 580 \\
\hline 3 & 0.900 & $1.615274 \mathrm{E} 6$ & $1.820801 \mathrm{E} 6$ & $33 \pm 1.08$ & 179 & 518 \\
\hline 4 & 1.33 & $1.455039 \mathrm{E} 6$ & $1.617207 \mathrm{E} 6$ & $23 \pm 1.3$ & 298 & \\
\hline
\end{tabular}

temperature range varies from room temperature to $\sim 90^{\circ} \mathrm{C}$. The experimental TCF for a non-coated resonator was $73 \mathrm{ppm} /{ }^{\circ} \mathrm{C}, 32 \%$ higher than FEA prediction $\left(55 \mathrm{ppm} /{ }^{\circ} \mathrm{C}\right)$. This discrepancy is attributed to the TCE mismatch between the silicon substrate and the Pyrex shell. The characterization results showed a clear reduction of the TCF for the spherical resonator by increasing the thickness of Ti metal. In particular, a reduction of $70 \%$ was achieved by using 1.33 um film of metal.

Table II shows a summary of the characterization results. Importantly, in all devices that have been characterized, the Q factor does not decrease significantly upon application of the titanium coating. The study of the effect on Q is outside the scope of this paper.

\section{CONCLUSIONS}

This work demonstrates a viable approach for permanent TCF reduction in micro glass-blown Pyrex spherical resonators for high frequency applications. A metal coating fabrication step has been added at the end of an established micro glassblowing fabrication process. Experimental results demonstrate the use of $\mathrm{Ti}$ as compensation layer. TCF reduction from $73 \mathrm{ppm} /{ }^{\circ} \mathrm{C}$ to $25 \mathrm{ppm} /{ }^{\circ} \mathrm{C}$, without affecting the Q-factor of the $\mathrm{n}=2$ resonant mode was demonstrated with an application of 1.33um Ti coating. The use of Ti mitigates the risk of dramatic temperature induced frequency drift on glass-based mechanical structures, and provides a convenient path for defining electrodes for electrostatic actuation.

\section{ACKNOWLEDGMENTS}

This work was supported by DARPA/SPAWAR under Grant N66001-10-1-4074. Devices were designed, developed, and tested in UCI Micro-Systems Lab. Authors would like to acknowledge UCI INRF and UCLA NRF staff for help and valuable suggestions on the fabrication aspects of this project.

\section{REFERENCES}

[1] Nguyen, C.T.-C., "MEMS technology for timing and frequency control," IEEE Transactions on Ultrasonics, Ferroelectrics and Frequency Control, ,vol.54, no.2, pp.251-270, 2007

[2] Tabatabaei, S.; Partridge, A., "Silicon MEMS Oscillators for HighSpeed Digital Systems," IEEE J. Microelectromech. Syst .vol.30, no.2, pp.80-89, 2010

[3] Lam, C. S., "A review of the recent development of MEMS and crystal oscillators and their impacts on the frequency control products industry," IEEE Ultrasonics Symposium, 2008. pp.694-704
[4] Pai, P.; Chowdhury, F.K.; Pourzand, H.; Tabib-Azar, M., "Fabrication and testing of hemispherical MEMS wineglass resonators," IEEE MEMS 2013. pp.677-680, 20-24 Jan. 2013.

[5] Sorenson, L.D.; Gao, X.; Ayazi, F., "3-D micromachined hemispherical shell resonators with integrated capacitive transducers," IEEE MEMS 2012, pp.168-171, Jan. 29 -Feb. 22012

[6] Sarac, B.; Kumar, Golden; Hodges, T.; Ding, Shiyan; Desai, A.; Schroers, Jan, "Three-Dimensional Shell Fabrication Using Blow Molding of Bulk Metallic Glass," IEEE J. Microelectromech. Syst. vol.20, no.1, pp.28-36, 2011

[7] Cho, J.; Yan, J.; Gregory, J.A.; Eberhart, H.; Peterson, R.L.; Najafi, K., "High-Q fused silica birdbath and hemispherical 3-D resonators made by blow torch molding," IEEE MEMS 2013 pp.177-180, 2013

[8] Senkal, D.; Ahamed, M.J.; Trusov, A.A.; Shkel, A.M., "Achieving Sub$\mathrm{Hz}$ Frequency Symmetry in Micro-Glassblown Wineglass Resonators," IEE J. Microelectromech. Syst. vol.PP, no.99, 2013

[9] Eklund, E.J.; Shkel, A.M., "Glass Blowing on a Wafer Level," IEEE J Microelectromech. Syst, vol.16, no.2, pp.232-239, 2007.

[10] Prikhodko, I.P.; Zotov, S.A.; Trusov, A.A.; Shkel, A.M., "Microscale Glass-Blown Three-Dimensional Spherical Shell Resonators," IEEE J. Microelectromech. Syst, vol.20, no.3, pp.69-,701, 2011

[11] Zotov, S.A.; Trusov, A.A.; Shkel, A.M., "Three-Dimensional Spherical Shell Resonator Gyroscope Fabricated Using Wafer-Scale Glassblowing," IEE J. Microelectromech. Syst, vol.21, no.3, pp.509-510, 2012

[12] Zhengzheng Wu; Peczalski, A.; Thakar, V.A.; Zongliang Cao; Yi Yuan; Guohong He; Peterson, R.L.; Najafi, K.; Rais-Zadeh, M. "Piezoelectrically transduced high-Q silica micro resonators," IEEE MEMS 2013,pp.122-125, 20-24 Jan. 2013

[13] van Beek, J. T. M.; Puers, R "A review of MEMS oscillators for frequency reference and timing applications" IOP Journal of Micromechanics and Microengineering, vol. 22, pp. 013001. 2011

[14] Abdolvand, R.; Mirilavasani, H.; Ayazi, F.; "A low-voltage temperature stable micro-mechanical piezoelectric oscillator" IEEE Transducers 2009 vol 1, pp 53-56, 2009

[15] Samarao, A.K.; Ayazi, F.; "Temperature compensation of silicon micromechanical resonators via degenerate doping" IEEE Int. Electron Devices Meeting (IEDM) 2009 pp 1-4. 2009

[16] Ho, G.K.; Sundaresan, K.; Pourkamali, S. Ayazi, F.; " Low motional impedance highly tunable $\mathrm{I} 2$ resonators for temperature compensated reference oscillators" IEEE MEMS 2005 pp 116-120, 2005

[17] Sundaresan K, Ho G K, Pourkamali S and Ayazi F "Electronically temperature compensated silicon bulk acoustic resonator reference oscillators" IEEE J. Solid-State Circuits 2007 Vol. 42 1425-1434

[18] Ruffieux D, Pezous A, Pliska A-C and Krummenacher F "Siliconresonator-based, $3.2 \mu \mathrm{W}$ real-time clock with $\pm 10 \mathrm{ppm}$ frequency accuracy" Tech. Dig. IEEE Int. Solid-State Circuits Conf., ISSCC 2009 pp 214-234.

[19] Rai, S.; Ying, S.; Wei, P.; Ruby, R.; and Otis, B.; " A digitally compensated $1.5 \mathrm{GHz}$ CMOS/FBAR frequency reference" IEEE Trans. Ultrason. Ferroelectr. Freq. Control 2010 Vol. 57 pp.552-561, 2010

[20] Melamud, R.; Chandorkar, Saurabh A.; Bongsang, K.; Lee, H-K; Salvia, J.C.; Bahl, G.; Hopcroft, M.A.; Kenny, T.W., "TemperatureInsensitive Composite Micromechanical Resonators" IEEE J Microelectromech. Syst, vol.18, no.6, pp.1409-1419, 2009 